\title{
Challenges in diagnosis and management of neutropenia upon exposure to immune- checkpoint inhibitors: meta-analysis of a rare immune-related adverse side effect
}

J. Boegeholz', C. S. Brueggen², C. Pauli², F. Dimitriou², E. Haralambieva ${ }^{3}$, R. Dummer², M. G. Manz ${ }^{1}$ and C. C. Widmer ${ }^{1 *}$

\begin{abstract}
Background: Cancer immunotherapy via immune-checkpoint inhibition (ICI) by antibodies against cytotoxic Tlymphocyte-associated protein 4 (CTLA-4) and cell death protein 1 (PD-1) have significantly improved the outcome of metastasized melanoma and of a rapidly increasing number of other cancer types. The anti-tumor effect is often accompanied by immune-related adverse events (irAE). Hematological irAE, specifically neutropenia, are rarely observed. However, neutropenia is associated with high morbidity and mortality due to infection complications. Thus, early detection and treatment is crucial.
\end{abstract}

Methods: We present the clinical course of two patients with severe neutropenia after ICl therapy and demonstrate the difficulty of the diagnosis when a comedication of metamizole, a well-known analgesic drug used to treat cancer pain, is present. Further, we provide a comprehensive descriptive and statistical analysis of published data on diagnostics, treatment and infection complication in patients with at least grade 4 neutropenia by a systematic database search.

Results: Finally, 34 patients were analyzed, including the two case reports from our cohort. The median onset of neutropenia was 10.5 weeks after first $\mathrm{ICl}$ administration (interquartile range: 6 weeks). In $76 \%(N=26)$, a normalization of the neutrophil count was achieved after a median duration of neutropenia of 13 days. In a subsample of 22 patients with detailed data, the infection rate was 13\%, proven by positive blood culture in 3 cases, but $68 \%(N=15)$ presented with fever $>38^{\circ} \mathrm{C}$. Treatment regime differed relevantly, but mainly included G-CSF and intravenous corticosteroids. Death was reported in 14 patients (41\%), 3 of whom (9\%) were associated with hematological irAE but only two directly associated with neutropenia.

Conclusion: With an increasing number of cancer patients eligible to ICI therapy, the incidence of severe hematological toxicities may rise substantially over the next years. Clinicians working in the field of cancer immune therapies should be aware of neutropenia as irAE to provide immediate treatment.

Keywords: Immune-checkpoints-inhibitor, Neutropenia, Metamizole, Hematological side effects, Immune-related adverse events

\footnotetext{
* Correspondence: corinne.widmer@usz.ch

'Department of Medical Oncology and Hematology, University and University Hospital Zurich, Zurich, Switzerland

Full list of author information is available at the end of the article
}

(C) The Author(s). 2020 Open Access This article is licensed under a Creative Commons Attribution 4.0 International License, which permits use, sharing, adaptation, distribution and reproduction in any medium or format, as long as you give appropriate credit to the original author(s) and the source, provide a link to the Creative Commons licence, and indicate if changes were made. The images or other third party material in this article are included in the article's Creative Commons licence, unless indicated otherwise in a credit line to the material. If material is not included in the article's Creative Commons licence and your intended use is not permitted by statutory regulation or exceeds the permitted use, you will need to obtain permission directly from the copyright holder. To view a copy of this licence, visit http://creativecommons.org/licenses/by/4.0/ The Creative Commons Public Domain Dedication waiver (http://creativecommons.org/publicdomain/zero/1.0/) applies to the data made available in this article, unless otherwise stated in a credit line to the data. 


\section{Background}

Cancer immunotherapy by immune-checkpoint inhibition (ICI) of the cytotoxic T-lymphocyte-associated Protein 4 (CTLA-4) and programmed cell death protein 1 (PD-1) and its ligand (PD-L1) has significantly improved the treatment of metastasized melanoma [1]. It is also successfully being used to treat patients with advanced stage lung cancer, lymphoma, kidney and bladder cancer and an increasing number of other cancer types [2]. The physiological role of CTLA-4 and PD-1 mediates protection against autoimmunity and promotes self-tolerance [3]. By blocking CTLA-4 or PD-1 function, the host immune response against cancer cells is enhanced. However, due to the activation of the immune system, a wide spectrum of immune-related adverse events (irAEs) may occur. The organs most affected are skin, lungs, intestine, endocrine glands and liver, but irAEs can also occur in several other organ systems $[4,5]$. The combination of CTLA4 and PD1 blockade increase the antitumor efficacy but, concurrently, also the rate of irAEs [6]. While hematological side effects have been rarely reported, the consequences of bone marrow dysfunction resulting in severe neutropenia is potentially lethal due to the high risk of bacterial or fungal infection, especially if neutropenia is prolonged [7]. As the overall incidence of neutropenia as irAE in cancer patients treated with ICI-therapy is low [8], only a few articles with patient data are available in the literature [9-32]. Some of these cases have been summarized in a recent descriptive observational study on hematological irAE [33]. Generally, the treatment procedure of irAE consists of discontinuation of the ICI therapy and administration of corticosteroids [34]. This therapy regimen could be contraindicated for patients with severe neutropenia, as the application of corticosteroids in this context might further increase the risk of infection [35]. Neutropenia as irAE in the hematopoietic system is multifaceted and the exact pathophysiological mechanism leading to bone marrow failure is still unknown. While anticancer drugs like chemotherapy are well recognized as causes of neutropenia, there are other drugs used in cancer treatment, that may cause neutropenia. This can lead to difficulties in determining the causative drug of the neutropenia as well as its treatment. In general, severe neutropenia as an adverse drug reaction is well known, for example in the case of metamizole (Novaminsulfon, Dipyrone), a popular and well-known antipyretic and analgesic drug. The treatment of drug-induced neutropenia consists of G-CSF and, if signs of infection are present, empiric antibiotic treatment with reconstitution within a few days [36]. However, several countries, such as the United States and the United Kingdom, have withdrawn metamizole from the market due to this adverse side effect. In most parts of Europe and Latin America, it is still broadly administered and successfully used to treat cancer pain [37]. Therefore, the combination therapy of metamizole and ICI is not so farfetched and neutropenia in these patients poses challenges in diagnosis and treatment. We present the clinical course of two patients who were given this particular drug combination, with the documented reproducible irAE of severe neutropenia due to the ICI therapy in one of the cases. We supplement this report with a retrospective clinical data analysis of published clinical courses of patients with neutropenia as irAE after ICI treatment.

\section{Methods}

\section{Patients selection}

Adult patients with severe grade 4 neutropenia probably or certainly associated to every kind of ICI were independently searched by two authors, using PubMed search (http://www.ncbi.nlm.nih.gov). All case reports published in English language before the 14th of November 2019 were included. The terms "neutropenia", "leucopenia", and "pancytopenia" were combined ("AND") with one or more of the following words: "immune checkpoint inhibitor", "cytotoxic T-lymphocyte-associated Protein 4", "antiprogrammed cell death 1", "anti-programmed cell death ligand 1", "ipilimumab", "nivolumab”, "pembrolizumab”, "atezolizumab", "avelumab", and "durvalumab". Data on age, cancer disease, dosage and type of ICI, onset and duration of neutropenia, salvage therapy, other irAE, infection complications, blood and bone marrow results were collected and analyzed as described by the authors. The two patients described in this manuscript provided their informed consent; procedures were in accordance with the ethical standards of the responsible committee on human experimentation and with the Declaration of Helsinki.

\section{Statistical analysis}

Analysis were done using Mann-Whitney U or KruskalWallis test and contribution of factors to fever was tested by chi-square test. Duration of neutropenia was analyzed with log-rank test; correlations were quantified by Spearman's rho. Statistical analyses were performed using SPSS Version 20.0 and RStudio 1.2.

\section{Results \\ Case presentation}

Our first case, a 65-year old patient with lentigo maligna melanoma tumor stage IV (pT4b, N2b M1b), was initially treated with pembrolizumab (anti-PD1) and progressed in June 2016. A combination therapy with ipilimumab (anti-CTLA4) and nivolumab (anti-PD1) was initiated. At the beginning of the fourth cycle, a severe grade 4 neutropenia $(0,01 \mathrm{G} / \mathrm{l})$ with normal hemoglobin, thrombocyte and lymphocyte levels was documented. A detailed time line of medication application and side 
effects is shown in Fig. 1. A broad-spectrum antibiotic therapy was started and the patient was admitted to our ward. Due to the fact that the patient previously received a co-medication of metamizole (Novalgin', SanofiAventis AG) and clozapine (Leponex ${ }^{\oplus}$, Novartis Pharma AG), with known side effects of severe neutropenia, a drug-induced cause of the isolated neutropenia was hypothesized. Bone marrow puncture at this time point revealed a nearly absent myelopoiesis without any other abnormalities. Histological analysis revealed small infiltrates of CD8 predominant lymphocytes. Stimulation with G-CSF (0,5 Mio. IE/kg daily) was immediately started at day 1. Due to persistent neutropenia for 9 days, corticosteroid treatment was added (methylprednisolone $1 \mathrm{mg} / \mathrm{kg}$ daily i.v.). Neutrophil recovery was reached 4 days later, overall 35 days after the last ICI application. Staging at this timepoint showed a partial response (Fig. 2). Upon interdisciplinary discussion with the patient and complete resolution of the neutropenia, he was re-exposed to nivolumab monotherapy with careful monitoring and without metamizole co-medication as metamizole was thought to be the cause of neutropenia. Four weeks later, a recurrence of grade 4 neutropenia $(0.01 \mathrm{G} / \mathrm{l})$ occurred. Corticosteroid treatment and G-CSF stimulation as mentioned above were immediately restarted. The neutrophil recovered to normal values 1 week after supportive therapy was started. However, the patient suffered from a severe pulmonary infection and hemorrhagic diarrhea and died due to respiratory failure and septic shock 1 week later. The autopsy result showed an advanced fungal lung infection, most likely stemming from the repeated neutropenia, and a marked colitis with ulcerous skip lesion (Fig. 3). Histological findings from the colon showed intestinal stromal infiltration of lymphocytes, matching an immune-related cause. Strikingly, further findings confirmed a complete remission of the advanced melanoma.

The second case occurred in November 2018. A 56year old patient with BRAFV600E metastatic melanoma stage IV (TxN3M1d), who was previously treated with

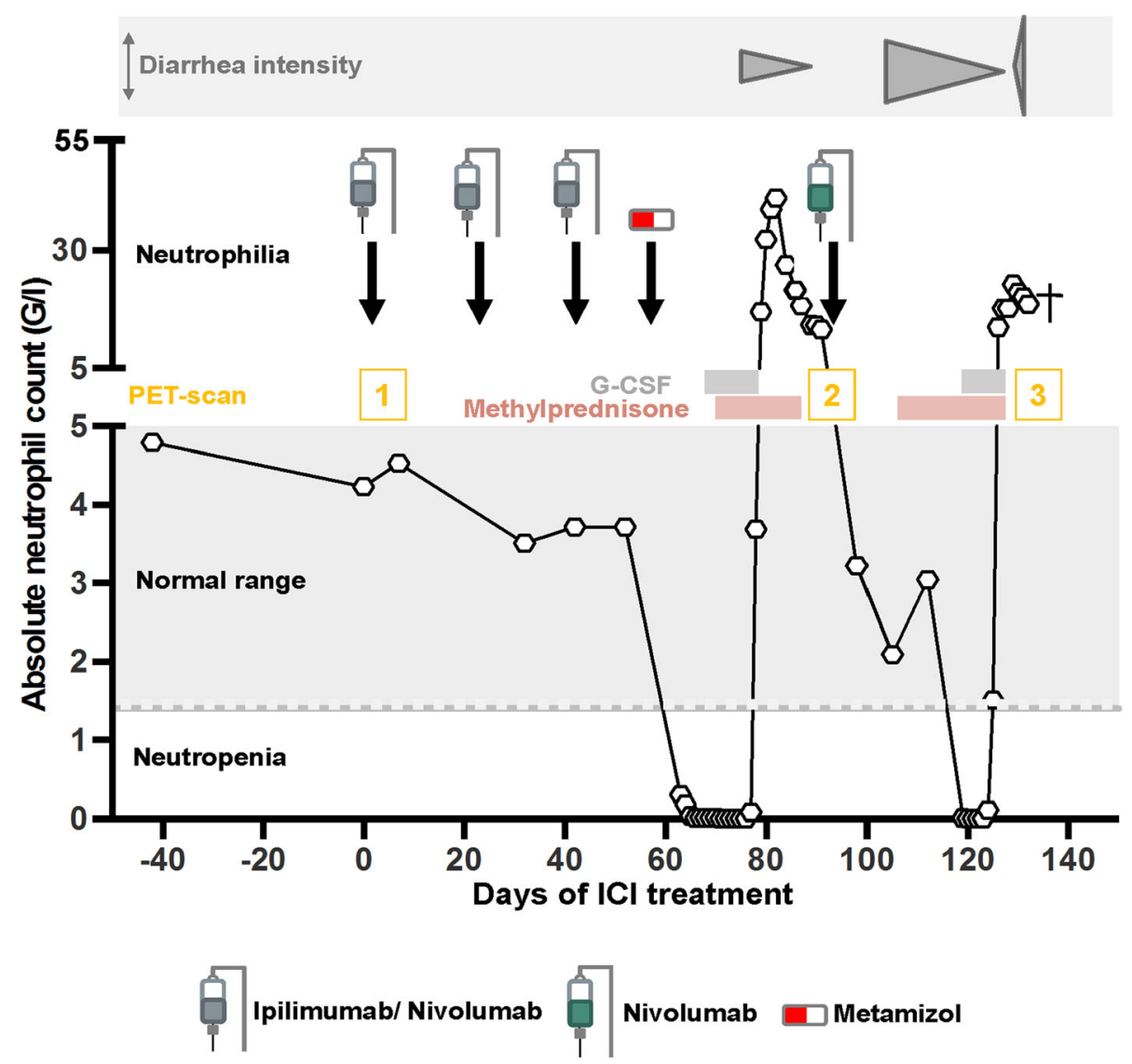

Fig. 1 Timeline of patient 1. Neutrophil count over time following administration of ipilimumab, nivolumab and metamizol as well as subsequent interventions (application of G-CSF and methylprednisolone) are shown. The lower grey band marks the thresholds of neutrophils in the blood. The upper grey band shows concurrent diarrhoea that was intermittently active between and during events of neutropenia. Numbers in yellow indicate the time point of positron emission tomography (PET) with images shown in Fig. 2. The black cross marks the death of the patient 


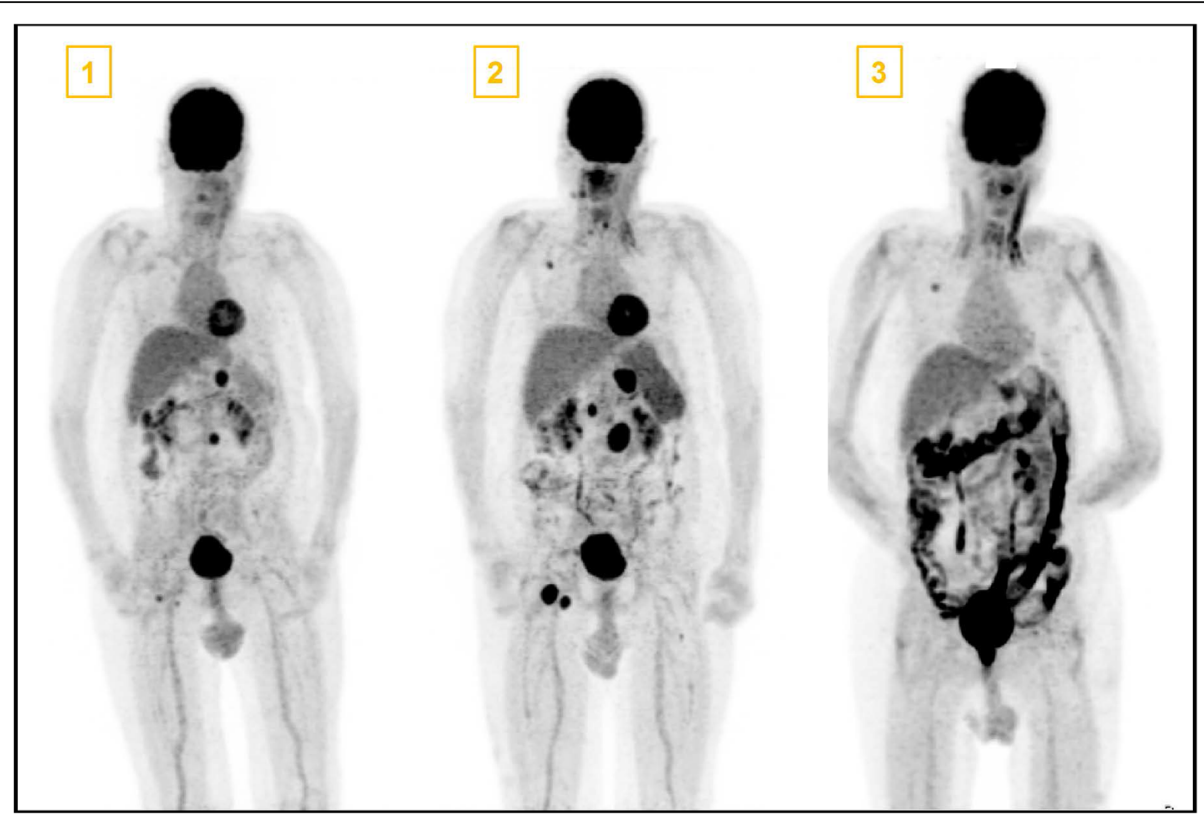

Fig. 2 Positron emission tomography (PET) images at the time points as shown in Fig. 1. PET Number 1 depicts multiple metastasis (coeliacal, inguinal, pulmonary and retroperitonal). In PET image 2 a progression with coeliacal, retroperitoneal, paraaortal and inguinal lymph node but decreasing pulmonary melanoma manifestations was seen as mixed response after 3 cycles of ipilimumab and nivolumab therapy. PET image 3 shows complete remission of melanoma metastasis and a high activity in the whole colon due to massive Immune Checkpoint Inhibitor induced colitis. The patient received a port-a-cath system between the first and second PET scan

chemotherapy (dacarbazine), BRAF inhibitor (vemurafenib), ipilimumab and pembrolizumab. After disease progression in July 2018, he was treated with nivolumab and additionally with anti-LAG-3 (NCT01968109). He presented with fever and an isolated grade 4 neutropenia ( 0.0 G/l) after 3 cycles of treatment and 26 days after the last infusion of nivolumab and anti-LAG-3. Additionally, he was treated with a maximal dose of metamizole $(4 \times 1 \mathrm{~g})$ due to cancer-related pain for 87 days. Immediate G-CSF application was started and 4 days later, prednisone 1 $\mathrm{mg} / \mathrm{kg} / \mathrm{d}$ was added, which was switched to methylprednisolone treatment another 4 days later. Intravenous Immunoglobulin (IVIG) (total dose of $1 \mathrm{~g} / \mathrm{kg}$ ) were applicated on days 9 to 11 after the diagnosis of neutropenia. Due to prolonged neutropenia, the initial broadband antibiotic therapy was supplemented with antimycotic therapy. Without any further complications, neutrophils recovered to normal values at day 15 after the initial episode. Bone marrow examination at day 4 confirmed an isolated complete absence of the myelopoiesis and showed a slight lymphocytosis of mostly CD8-positive $\mathrm{T}$-cells. The following staging showed a progressive disease, ICI treatment was permanently discontinued and the patient received Dabrafenib and Trametinib (BRAF and MEK inhibitor) therapy, without any signs of intolerance. The patient was still alive in the last follow up, 3 months after ICI-treatment initiation. He was not re-exposed to metamizole.

\section{Systematic review \\ Literature search}

Twenty-nine articles matching our defined search criteria were identified. Four articles presenting meta-analyses with main focus of incidence of irAE were not included as detailed information were not provided $[4,8,38,39]$. One observational study, which included previously published case reports, was excluded as it showed an overlap of case reports with our study but was further used for comparison of the results [33]. A second observational study presented summarized patient data but did not present reviewable information on detailed clinical course and it could only be partially included in the analysis [27]. Meeting the criteria of grade 4 neutropenia upon ICI exposure, 22 patients with detailed clinical course were identified through the PubMed search. Two case reports were excluded as we interpreted it to be unlikely that the reported neutropenia was caused by ICI [31, 32]. A detailed selection flow chart is shown in Fig. 4. Finally, we used 34 cases for the assessment of main characteristics and salvage therapy, duration of neutropenia and outcome and 22 cases for the analysis of non-hematological irAE on duration of neutropenia, clinical presentation and infection complication.

\section{Meta-analysis: Main characteristics of patients with neutropenia upon $\mathrm{ICl}$ and additional irAE}

Table 1 displays the main patient characteristics of the 32 published cases and the two cases described above. 


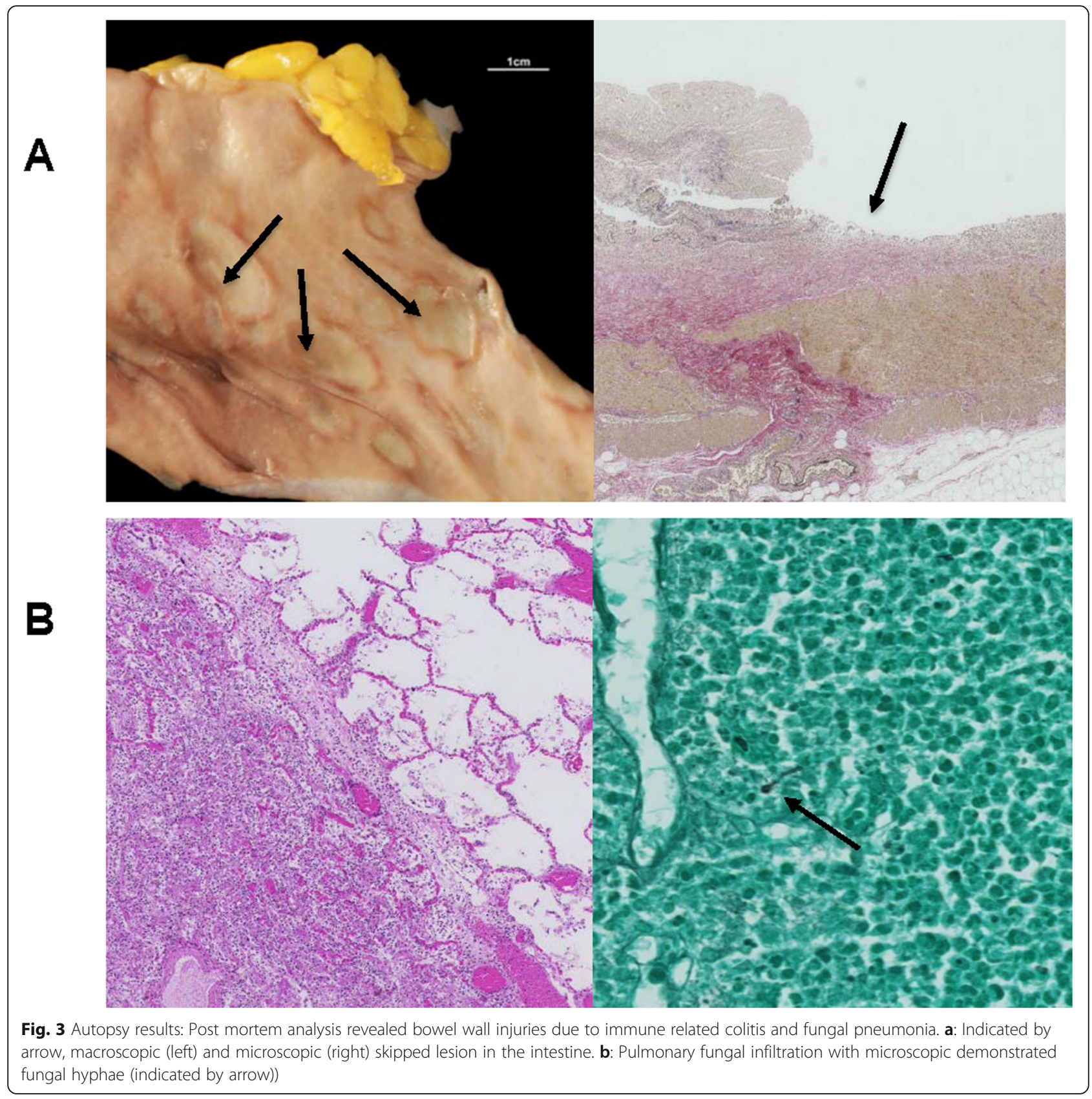

Isolated neutropenia was found for 11 patients (32\%). In 5 cases the authors did not comment on other blood values, thus it can only be assumed that there was no other cytopenia present. Anemia was additionally reported in 16 cases (55\%, median: $94 \mathrm{~g} / \mathrm{l})$. Of these, 7 patients presented an additional thrombocytopenia (all below $100 \mathrm{G} / \mathrm{l}$ ) and were therefore classified as an ICIinduced pancytopenia (20\%). The combination of neutropenia and thrombocytopenia without anemia was not observed. Twenty cases reported on the presence or absence of additional irAE (rash, hepatitis, colitis; endocrine, pneumonitis) and for the others it was not documented. Isolated hematological irAE occurred in 9 cases $(40 \%)$, while the others presented with prior or additional irAE.

\section{Meta-analysis of onset and duration of neutropenia, clinical presentation and infection rate}

The median onset of the neutropenia was 10.5 weeks after the first dose of ICI therapy (min. 2.2, max. 25.4, interquartile range: 6 weeks). Adapted to the last ICI infusion the median time until neutropenia was documented after the last given dose was 12 days ( $\min .3$, max 26, interquartile range 8 days). Neutropenia occurred 


\section{Database search result}

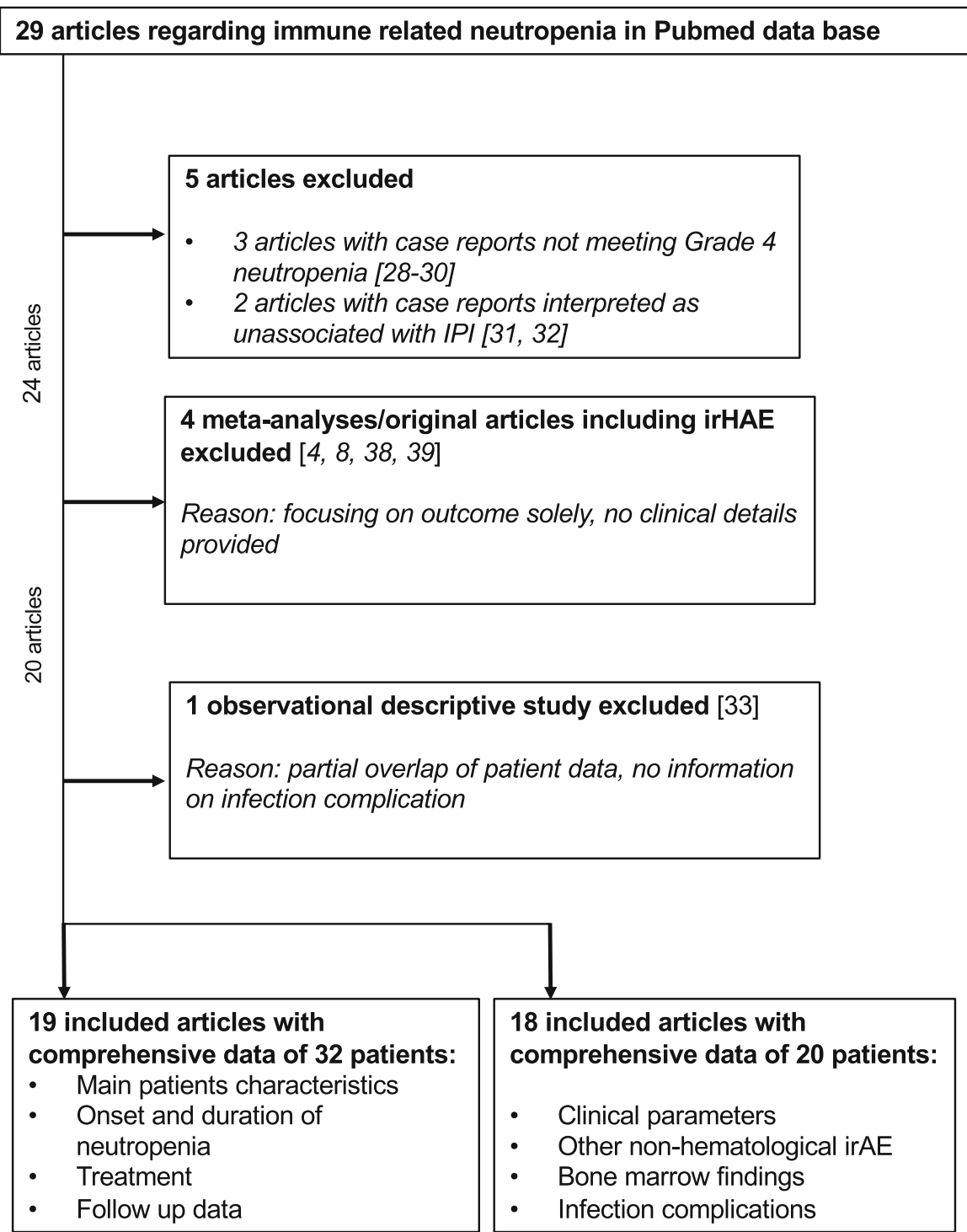

Fig. 4 Patients selection flow chart meeting the search criteria. Final patient cohort. Overall 34 patients were selected. Due to a lack of detailed clinical information, an article with 9 patients could not be used for certain subanalysis

mostly between the third and fourth cycle of the therapy (min. 1, max. 11 cycles, median 3.0 cycles). There was no statistical influence on time of onset of neutropenia regarding age or sex, underlying cancer disease, type of ICI treatment or additional presence of other nonhematological irAE (Fig. 5). Anemia was associated with a shorter onset of neutropenia $(r=0.49 ; p=0.03)$, while thrombocyte values showed no statistically significant correlation ( $p=0.22)$ (Additional Fig. 1). Further clinical details were available for 22 patients. The majority of them $(N=15,68 \%)$ had a clinical presentation with fever $>38^{\circ} \mathrm{C}$ at the time point of diagnosis of neutropenia and all of them were treated with broadband intravenous antibiotics. Chi-Square tests showed no relationship of the presence of fever with any of the following factors: gender $(p=0.59)$, disease (melanoma, lung cancer, lymphoma, or other cancers; $p=1.00$ ), ICI (anti-CTLA4, anti-PD1 or a combination of both; $p=0.69$ ), other irAE (no other irAE or more than 1 irAE; $\mathrm{p}=1.00)$, or onset of neutropenia (< 10 weeks or $>10$ weeks; $p=0.07$ ). Only three patients (13\%) had a bacterial infection, which was confirmed by positive blood cultures. Fungal infection was never observed at the initial neutropenic state. Of 16 cases (72\%), bone marrow examination at diagnosis of neutropenia or 
Table 1 Baseline demographics, diseases, treatments, side effects, blood values and infection parameters of 20 patients in reviewed case reports ( $y=$ years, $I \mathrm{Cl}=$ Immune Checkpoint Inhibitor, irAE $=$ Immune-related side effects, n.a. $=$ not applicable)

\begin{tabular}{|c|c|c|c|c|c|c|c|c|c|c|}
\hline Patient & $\begin{array}{l}\text { Age } \\
(y)\end{array}$ & Cancer disease & $\mathrm{ICl}$ & $\begin{array}{l}\text { irAE (besides } \\
\text { neutropenia) }\end{array}$ & $\begin{array}{l}\text { Neutrophil } \\
\text { count (G/l) }\end{array}$ & $\begin{array}{l}\text { Hemoglobin } \\
\text { values }(\mathrm{g} / \mathrm{l})\end{array}$ & $\begin{array}{l}\text { Thrombocyte } \\
\text { count }(\mathrm{G} / \mathrm{l})\end{array}$ & $\begin{array}{l}\text { Reported } \\
\text { strain }\end{array}$ & Fever & $\begin{array}{l}\text { Antibiotic } \\
\text { therapy }\end{array}$ \\
\hline 1 & 42 & Melanoma & Ipilimumab & Rush & 0.3 & 108 & 202 & None & Yes & Yes \\
\hline 2 & 74 & Melanoma & Ipilimumab & $\begin{array}{l}\text { Not } \\
\text { documented }\end{array}$ & 0 & 62 & 158 & None & Yes & Yes \\
\hline 3 & 77 & Melanoma & Ipilimumab & Endocrine & 0 & 88 & 71 & $\begin{array}{l}\text { R. plantocola } \\
\text { and E. cloacae }\end{array}$ & Yes & Yes \\
\hline 4 & 49 & Melanoma & Ipilimumab & None & 0 & Normal & Normal & None & Yes & Yes \\
\hline 5 & 70 & Melanoma & Ipilimumab & Rush & 0.3 & 70 & n.a. & None & No & n.a. \\
\hline 6 & 35 & Melanoma & Ipilimumab & None & 0 & 76 & 256 & None & Yes & Yes \\
\hline 3 & 54 & Melanoma & Ipilimumab & $\begin{array}{l}\text { Rush, } \\
\text { endocrine }\end{array}$ & 0 & n.a. & 127 & None & Yes & Yes \\
\hline 8 & 74 & $\begin{array}{l}\text { Lung cancer } \\
\text { (adenocarcinoma) }\end{array}$ & Nivolumab & $\begin{array}{l}\text { Rush, } \\
\text { hepatitis }\end{array}$ & 0 & n.a. & n.a. & S. aureus & No & Yes \\
\hline 9 & 48 & Melanoma & $\begin{array}{l}\text { Nivolumab and } \\
\text { ipilimumab }\end{array}$ & None & 0 & 115 & $<5$ & None & Yes & Yes \\
\hline 10 & 38 & $\begin{array}{l}\text { Primary mediastinal } \\
\text { B-cell lymphoma }\end{array}$ & Nivolumab & None & 0 & n.a. & n.a. & None & n.a. & n.a. \\
\hline 11 & 73 & $\begin{array}{l}\text { Lung cancer } \\
\text { (adenocarcinoma) }\end{array}$ & Nivolumab & Colitis & 0 & n.a. & n.a. & None & Yes & Yes \\
\hline 12 & 74 & $\begin{array}{l}\text { Lung cancer } \\
\text { (adenocarcinoma) }\end{array}$ & Nivolumab & None & 0 & 119 & 249 & None & n.a. & n.a. \\
\hline 13 & 57 & Glioblastom & Nivolumab & Rush & 0 & 68 & 5 & $\begin{array}{l}\text { Moxarella } \\
\text { catarrhalis }\end{array}$ & Yes & Yes \\
\hline 14 & 51 & Melanoma & $\begin{array}{l}\text { Nivolumab and } \\
\text { ipilimumab }\end{array}$ & Endocrine & 0 & 77 & 346 & None & n.a. & n.a. \\
\hline 15 & 56 & $\begin{array}{l}\text { Lunge cancer } \\
\text { (adenocarcoma) }\end{array}$ & Nivolumab & None & 0.1 & 100 & 40 & $\begin{array}{l}\text { Fusarium } \\
\text { solani }\end{array}$ & Yes & Yes \\
\hline 16 & 59 & Melanoma & $\begin{array}{l}\text { Nivolumab and } \\
\text { ipilimumab }\end{array}$ & $\begin{array}{l}\text { Rush, } \\
\text { hepatitis, } \\
\text { colitis }\end{array}$ & 0.3 & n.a. & n.a. & None & n.a. & n.a. \\
\hline 17 & 73 & $\begin{array}{l}\text { Lung cancer } \\
\text { (adenocarcinoma) }\end{array}$ & Pembrolizumab & $\begin{array}{l}\text { Not } \\
\text { documented }\end{array}$ & 0 & n.a. & n.a. & None & Yes & Yes \\
\hline 18 & 82 & $\begin{array}{l}\text { Lung cancer } \\
\text { (pleomorphic } \\
\text { carcinoma) }\end{array}$ & Pembrolizumab & Pneumonitis & 0.1 & Normal & Normal & None & Yes & Yes \\
\hline 19 & 65 & Melanoma & $\begin{array}{l}\text { Nivolumab and } \\
\text { ipilimumab }\end{array}$ & Colitis & 0 & 103 & 227 & None & Yes & Yes \\
\hline 20 & 56 & Melanoma & $\begin{array}{l}\text { Nivolumab and } \\
\text { anti-LAG-3 }\end{array}$ & None & 0 & 144 & 288 & None & Yes & Yes \\
\hline
\end{tabular}

during treatment with corticosteroid or G-CSF was available in detail. All bone marrow findings, except two, showed complete absence of the myeloid lineage. In the two cases without hypoplastic myelopoiesis, the bone marrow puncture was done 4, respectively 5 days before complete resolution of the neutropenia was achieved. In the vast majority, lymphocytosis was present but only few demonstrated a CD8+ T-cell lymphocyte infiltration by immunohistochemistry. No bone marrow biopsy showed a metastatic infiltration of cancer cells.

\section{Variety of salvage therapy performed and outcome}

The treatment regimens of neutropenia as irAE differed substantially among the 34 patients. Analyses of these results are summarized in Table 2. Most common was the treatment with G-CSF $(N=31,91 \%)$, mostly in combination with corticosteroids $(N=24,70 \%)$. IVIG were used in $35 \%$ of the cases $(N=12)$. If IVIG seemed to be effective, the available patient data showed a rapid response of 4 days (median). In 5 cases, additional immunosuppression with anti-thymocyte globulin (ATG) $(N=2)$ and/or cyclosporine was administered $(N=3)$. 

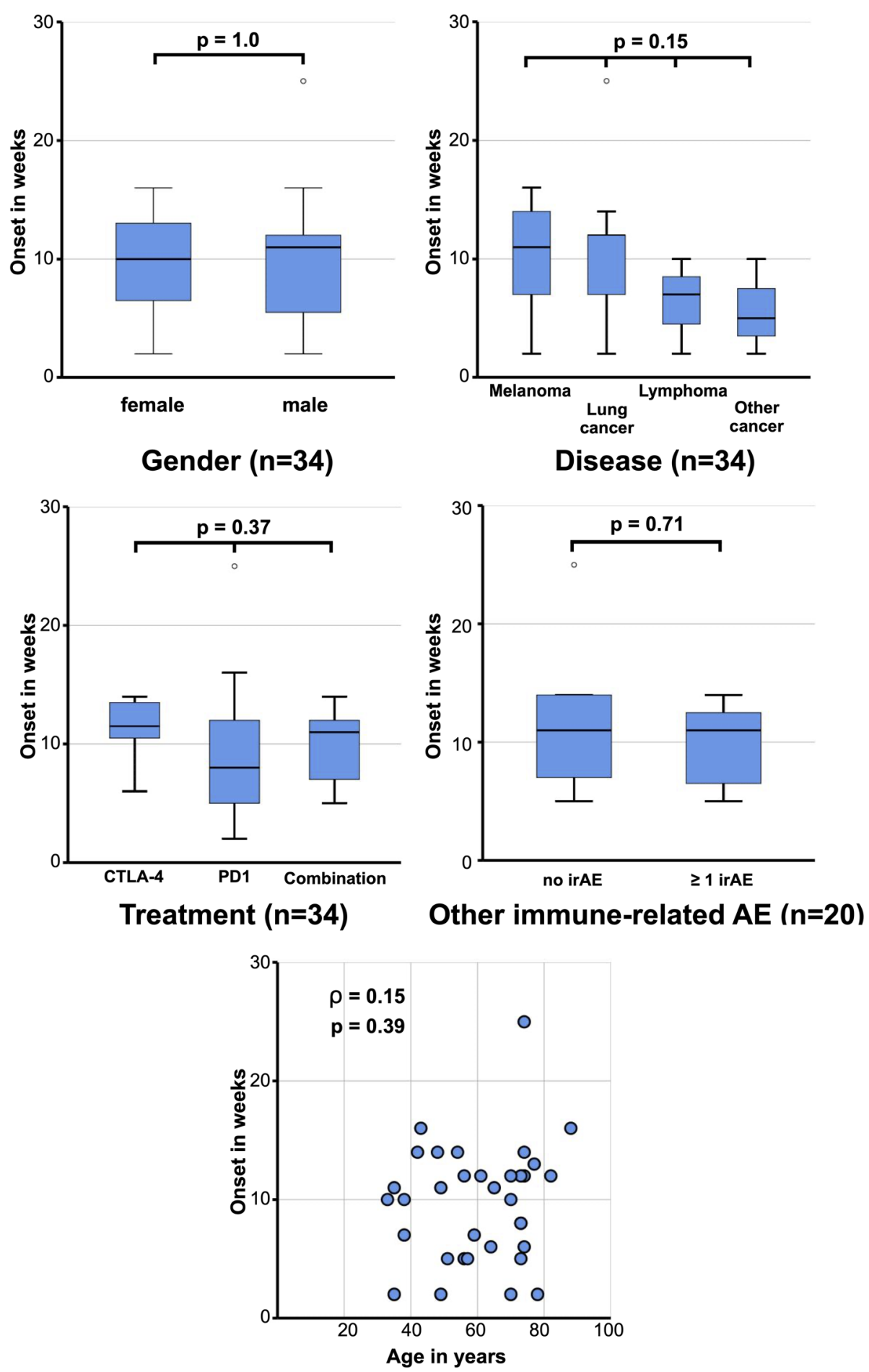

Fig. 5 Boxplots analysis for onset of neutropenia in weeks and scatterplot for correlation with age. Gender (a), Diseases (b), Treatment (c), other immune-related adverse events (d) and age in years (e). A p -value of 0.05 was defined as significant

The duration of neutropenia, defined as neutrophil recovery $>1 \mathrm{G} / \mathrm{l}$, was 13 days (min. 2, max 195, interquartile range 9.5 days). The duration of neutropenia differed not significantly between patients receiving IVIG or another salvage therapy while a shorter duration in two patients without steroids was observed $(p=0.04$, Additional Fig. 2), the latter possibly by a recovery before an initiation of any therapy for neutropenia. The vast majority ( $N=26,76 \%)$ demonstrated a normalization of the neutrophil count and no significant difference in response 


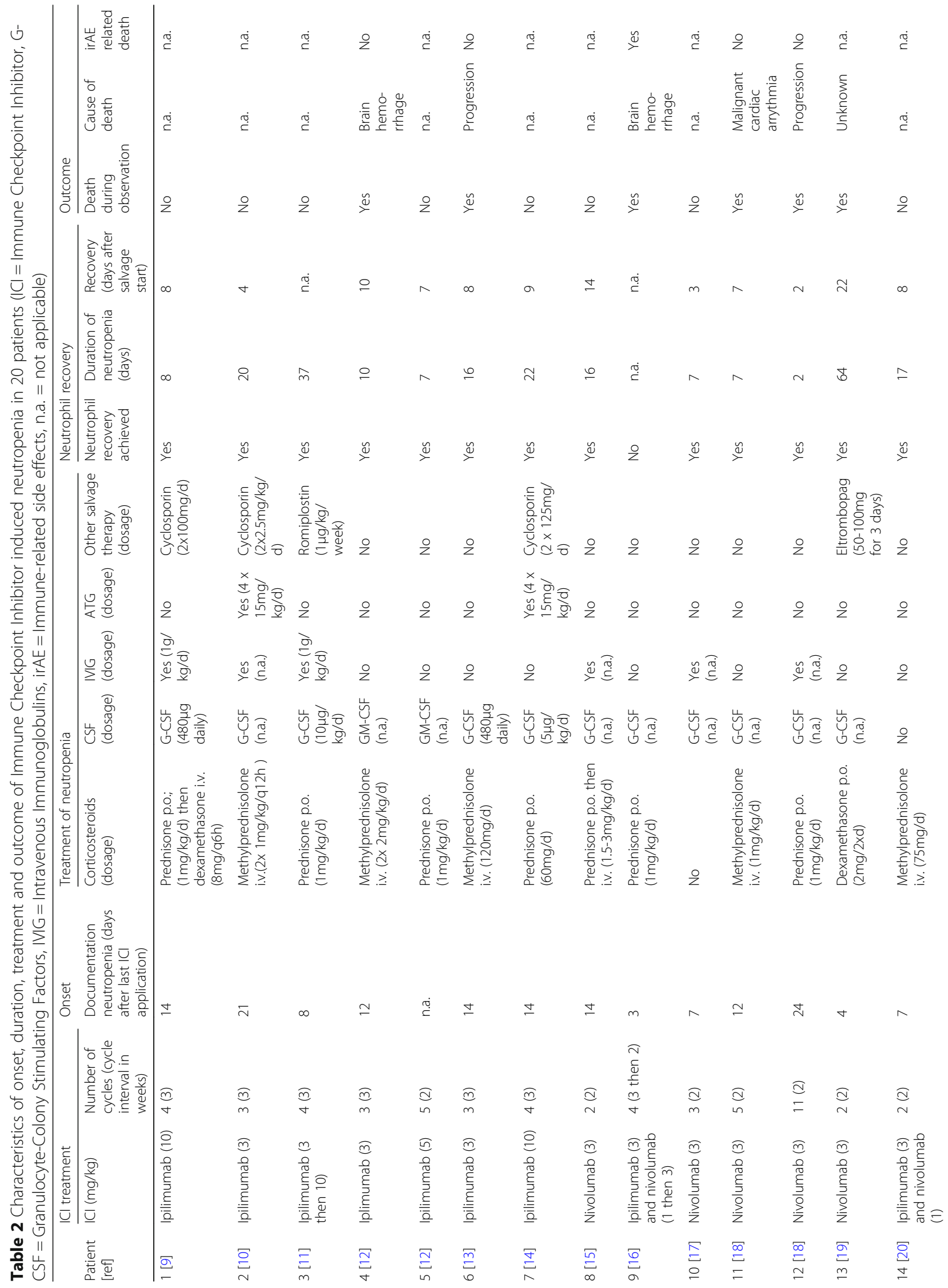




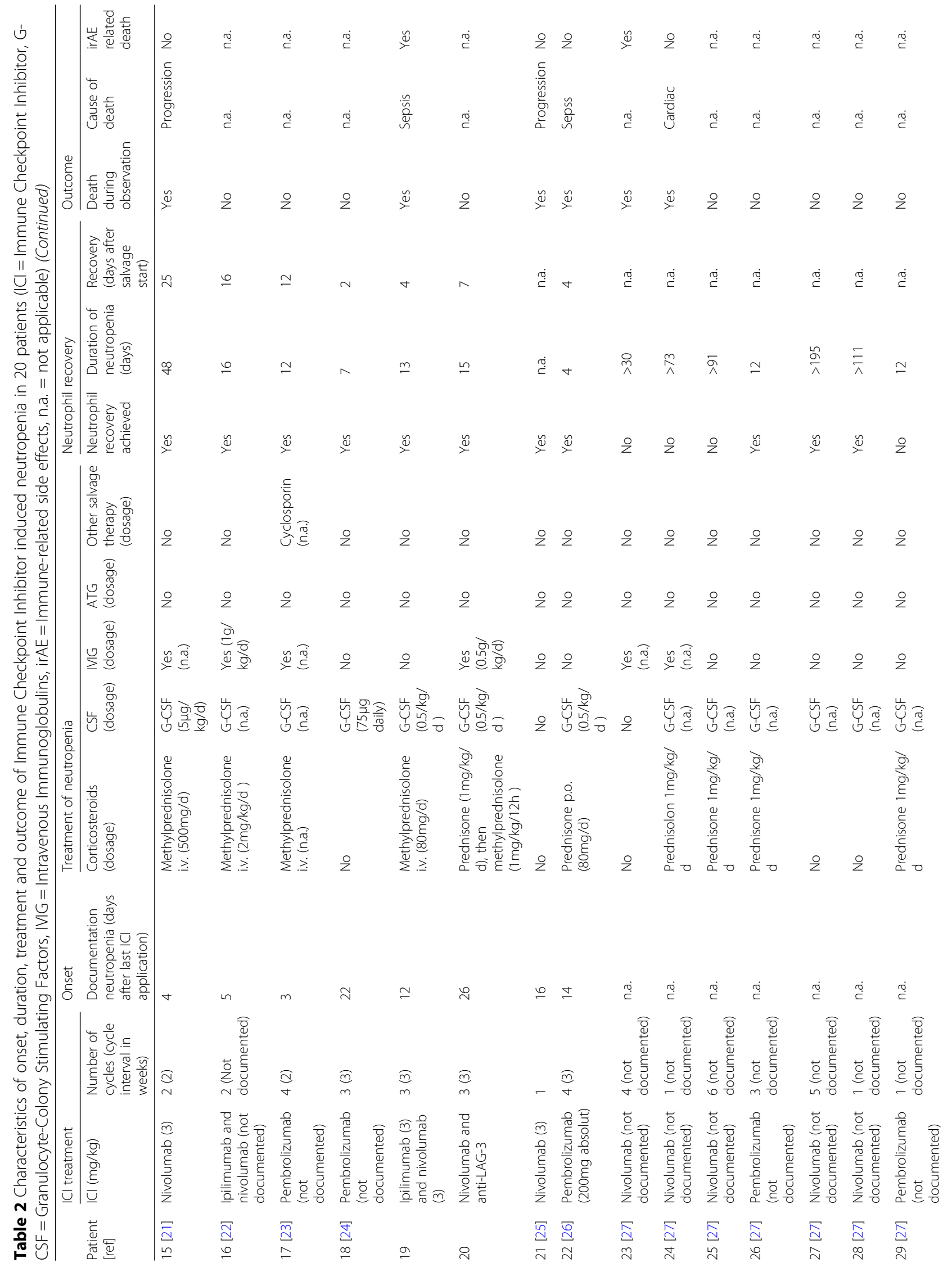




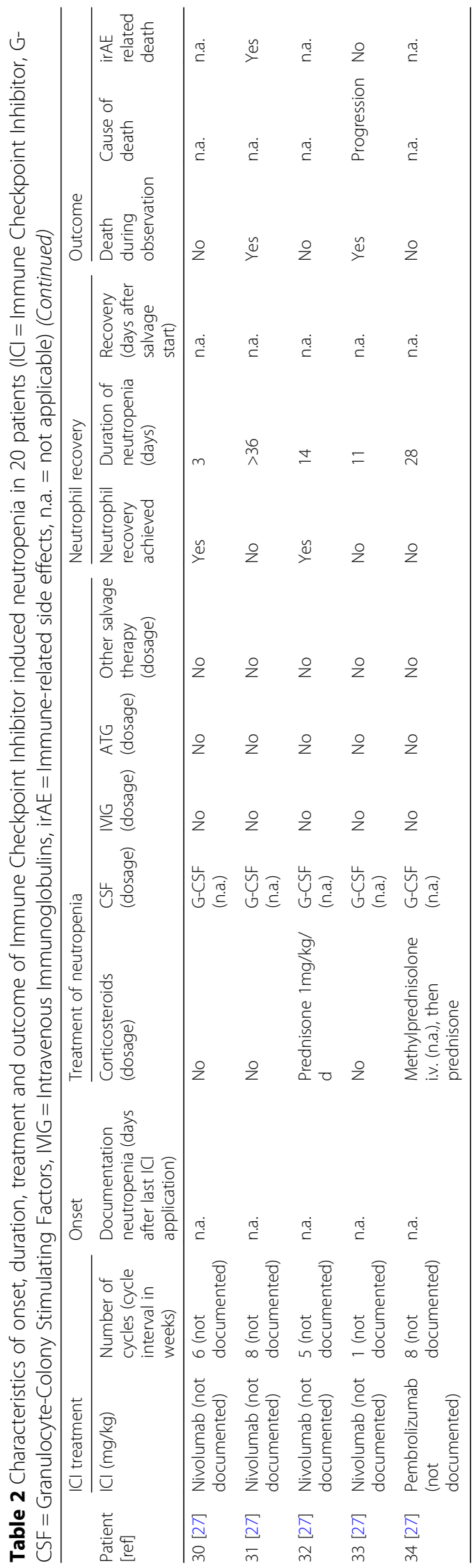


between patients with IVIG alone, or in combination of another salvage therapy (regardless of IVIG) was observed (Additional Fig. 3). For 8 patients, a relapse of the neutropenia during tapering or after the stop of corticosteroids was documented. Five patients, including our first case, were re-exposed to ICI and 4 of them (80\%) demonstrated a relapse of neutropenia. Our patient died after reexposition, the other patients survived. Despite a remarkable antitumor activity and severe side effects in some cases, we were not able to draw a conclusion about the response to ICI therapy due to the lack of reliable information and small number of patients. Death during observation period was reported for 14 (41\%), two of those as a consequence of ICI-induced neutropenia including our first case with fungal infection and one due to brain hemorrhage during severe thrombocytopenia [16]. In our study, we documented $9 \%$ of hematological irAE-associated deaths.

\section{Discussion}

Treatment with immune blockade of CTLA4 and PD1 cell surface proteins on lymphocytes and tumor cells results in remarkable anti-tumor activity $[40,41]$ but can be accompanied by severe irAE. The number of irAE will increase in the following years, due to the growing application success of ICI to multiple types of cancers. In line with this, a higher incidence of irAE against hematopoietic cells is conceivable.

Delanoy and colleagues have recently described an average time to onset of hematological irAE of 10.1 weeks, including 12 cases with neutropenia. These published case reports were also included in our case series. Our analysis of these 12 and additionally 22 other cases resulted in a comparable average onset of neutropenia as a hematological irAE of 11 weeks. This is translating to an occurrence mainly between the third or fourth cycle of any kind of ICI treatment. The median duration of neutropenia was 13 days, but it varied substantially. As a consequence of the retrospective nature of the data, possibly under-reported co-medications, and the inconsistent supportive treatment approaches, the duration of ICI-induced neutropenia must be interpreted with caution. Overall, $76 \%$ of the cases achieved a normalization of the neutrophils, which is in line with the finding of the published results of Finkel et al. [33], who have done a comparable analysis of 20 overlapping patients with our cohort $[9,15,17,18,21,25,27]$. Focusing on irAEs, they are suggested to arise from general immunologic enhancement and are often manageable by discontinuation of the ICI therapy and/or treatment with immunosuppressive drugs [34]. Potentially fatal outcomes warrant appropriate treatment of ICI-induced neutropenia. However, as recommended for irAEs, additional immune-suppressive drugs for patients developing neutropenia pose a treatment conflict, as the infection rate may be increased. Considering this, fever as a sign of systemic inflammation was one of the cardinal symptoms which led to the diagnosis of neutropenia overall. As a consequence, all of these patients received broadband antibiotic from the first day of diagnosis. Bacterial blood stream infection rate was documented in only $13 \%$ of the cases and was already confirmed before corticosteroid treatment was applied. Death due to infection associated with ICI-induced neutropenia happened as an exception. However, based on the data analysis presented here, treatment with G-CSF in combination with corticosteroids seems not to worsen outcomes concerning infection complications and presents an acceptable initial clinical treatment approach. An initial antifungal therapy does not seem to be mandatory, as the duration of ICI induced neutropenia was not prolonged in most of the cases. However, fungal infection should be kept in mind. A positive effect of IVIG has been observed in some, but not all cases, and should be used in combination with G-CSF and corticosteroids. Immunosuppression with cyclosporine and ATG might be effective, especially in patients with dysregulated effector T-cells [42]. On the basis of current knowledge, the use of immunosuppressive drugs for ongoing irAEs is controversial and still being discussed; therefore, prospective studies are needed [43]. Due to the limited data, it is unclear whether the standard of care therapy applied to ICI or the rate of spontaneous recovery of the neutrophils resolved the neutropenia, and therefore, it must be stated as a hypothesis.

Concurrent treatment with medications that can cause neutropenia is a diagnostic challenge in patients treated with ICI. Neutropenia is a known adverse side effect of drugs like metamizole and clozapine. The presence of the enzyme myeloperoxidase in neutrophil granulocytes leads to the oxidation of drugs into reactive metabolites and may function as a hapten, triggering an immune reaction $[44,45]$. These reactions occur restricted to certain individuals and therefore are called idiosyncratic drug reactions (IDR). Data for increased IDR in patients who received ICI are not available, but patients are possibly at a higher risk for IDR when their ability to immune tolerance is altered [46]. Drug-induced agranulocytosis seems to occur in $95 \%$ of the cases within the first 60 days of treatment [47]. Adapted to our second case, ICI and not metamizole-mediated neutropenia seems to be more probable, because of the timepoint of occurrence (between the third and fourth ICI therapy cycle) and because metamizole was taken continuously in maximal doses for a long period of time, namely 87 days. Bone marrow findings mentioned a growth-arrest of the myelopoiesis at the level of promyelocytes for metamizole, which implicates that the dividing pool and 
not the maturating pool of the myelopoiesis is susceptible to the metamizole immune-related toxicity. In our case series, bone marrow findings, except for one, showed an almost complete absence of the myelopoiesis. One case showed increased promyelocytes presence, but this particular finding occurred in a bone marrow taken 5 days before complete hematological reconstitution was reached. This might implicate a rather physiological finding during hematological recovery than a growth arrest of myelopoiesis. However, it demonstrates that bone marrow finding is time point-dependent and cannot provide a reliable distinction between ICI- or metamizole-induced neutropenia. Further, bone marrow lymphocytosis was present in some but not all cases and its function as a surrogate marker for immune-mediated neutropenia is difficult to prove. There is an ongoing discussion about the underlying mechanism of irAE [48]. Besides a T-cell mediated effect, an antibody driven process is suggested for neutropenia as irAE. Finkel and colleagues propose an interpretation of the underlying mechanism depending on the presence of antineutrophil antibodies and bone marrow finding [33]. This approach harbors difficulties. Measurement of antineutrophil antibody is not a standardized diagnostic approach to this very limited patient population and the absence of definable time points of bone marrow puncture in relation to the duration of neutropenia and treatment start will probably lead to misinterpretation of the bone marrow findings. The rarity of specific events in many different clinical settings is difficult to overcome and prospective comparing studies are needed with a focus on morphological, serological and histochemical findings in drugor ICI-induced neutropenia to clarify if there is a potential difference. Bone marrow puncture, however, should be recommended in suspected ICI-mediated neutropenia anyway to exclude bone marrow infiltration of metastases of the primary treated tumor, as then treatment approaches differ substantially.

\section{Conclusions}

In conclusion, the majorities of irAE upon ICI therapy occur within the first 4 months of treatment, matching the time point of appearance of neutropenia in the reviewed cases. Therefore, neutropenia as irAE, even if rare, is a side effect a clinician should be aware of and blood value measurement is recommended at the beginning of each cycle and of special interest in patients presenting with fever under ICI therapy. As a treatment option of neutropenia in these patients, it seems to be safe to administer intravenous corticosteroids additionally to the G-CSF treatment, even in inconclusive cases with comedication probably causing neutropenia. Broadband antibiotic therapy should be given in all cases with neutropenic fever and the fact that neutropenia relapsed during dose reduction of corticosteroids, points towards a management strategy with frequent blood value control and a slow tapering of the steroids in the follow-up of these patients. However, further data is needed to understand the exact mechanism and risk factors for bone marrow failure upon ICI therapy, possibly leading to a more sophisticated treatment approach.

\section{Supplementary information}

Supplementary information accompanies this paper at https://doi.org/10. 1186/s12885-020-06763-y.

Additional file 1. Scatterplots with correlation of onset of neutropenia in weeks for Hemoglobin (A) and Thrombocytes (B). Significance threshold was defined as $<0.05$.

Additional file 2. Kaplan-Meier curves for duration of neutropenia in days in a patient subpopulation Diseases (A) ICI Treatment (B) other immune-related adverse events $=\operatorname{irAE}(C)$. Neutropenia therapy with steroids (D), IVIG (+ Steroids) (E) and other secondary salvage therapy (+/IVIG) (F). Significance threshold was defined as $<0.05$

Additional file 3 Kaplan-Meier curves for response of salvage treatments in days for IVIG alone (A) other salvage therapy (+/-) IVIG (B). A $p$-value of $<0.05$ was considered significant.

\section{Abbreviations}

ATG: anti-thymocyte globulin; CTLA-4: cytotoxic T-lymphocyte-associated protein 4; ICl: immune-checkpoint inhibition; IDR: idiosyncratic drug reactions; irAEs: immune-related adverse events; IVIG: Intravenous Immunoglobulin; PD-1: cell death protein 1

\section{Acknowledgements}

Not applicable

\section{Authors' contributions}

JB: Collected and analyzed data, and wrote the manuscript. CSB: Collected data; CP: Collected data; FD: collected data and reviewed the manuscript; $\mathrm{EH}$ : Performed the histological examination of the bone marrow; RD: Performed manuscript review; MGM: Performed manuscript review; CCW: collected and analyzed data and wrote the manuscript. All authors read and approved the final manuscript.

Funding

Not applicable

Availability of data and materials

All data generated or analyzed during this study are included in this published article.

\section{Ethics approval and consent to participate}

Since this manuscript covers a retrospective secondary data analysis, no ethics approval was necessary. Furthermore, both patients gave their written informed consent to use their data.

\section{Consent for publication}

Both patients of our center gave their written informed consent for the publication of their data.

\section{Competing interests}

RD has consulting and/or advisory relationships Novartis, Merck Sharp \& Dhome (MSD), Bristol-Myers Squibb (BMS), Roche, Amgen, Takeda, Pierre Fabre, Sun Pharma, Sanofi outside the submitted work. All remaining authors have declared no conflicts of interest. 


\section{Author details}

${ }^{1}$ Department of Medical Oncology and Hematology, University and University Hospital Zurich, Zurich, Switzerland. ${ }^{2}$ Department of Dermatology, University and University Hospital Zurich, Zurich, Switzerland. ${ }^{3}$ Institute of Pathology and Molecular Pathology, University Hospital Zurich, Zurich, Switzerland.

Received: 22 July 2019 Accepted: 17 March 2020

Published online: 14 April 2020

\section{References}

1. Pardoll DM. Immunology beats cancer: a blueprint for successful translation. Nat Immunol. 2012;13:1129-32.

2. Topalian SL, Drake CG, Pardoll DM. Immune checkpoint blockade: a common denominator approach to Cancer therapy. Cancer Cell. 2015;27: 450-61. https://doi.org/10.1016/j.ccell.2015.03.001.

3. Haanen JBAG, Van Thienen H, Blank CU. Toxicity patterns with immunomodulating antibodies and their combinations. Semin Oncol. 2015.

4. Bertrand A, Kostine M, Barnetche T, Truchetet M-E, Schaeverbeke T. Immune related adverse events associated with anti-CTLA-4 antibodies: systematic review and meta-analysis. BMC Med. 2015;13:211. https://doi.org/10.1186/ s12916-015-0455-8.

5. Costa RLB, Carneiro BA, Rademaker A, Agulnik M, Villaflor VM, Matsangou M, et al. Toxicity profile of approved anti-PD1 monoclonal antibodies in solid tumors: A systematic review and meta-analysis of randomized clinical trials. J Clin Oncol. 2016;34(15_suppl):3064. https://doi.org/10.1200/JCO.2016.34. 15_suppl.3064

6. Wolchok JD, Kluger H, Callahan MK, Postow MA, Rizvi NA, Lesokhin AM, et al. Nivolumab plus Ipilimumab in Advanced Melanoma. N Engl J Med. 2013;369:122-33. https://doi.org/10.1056/NEJMoa1302369.

7. Viscoli C, Varnier O, Machetti M. Infections in Patients with Febrile Neutropenia: Epidemiology, Microbiology, and Risk Stratification. Clin Infect Dis. 2005:40(Supplement_4):S240-5. https://doi.org/10.1086/427329.

8. Sui J-D, Wang Y, Wan Y, Wu Y-Z. Risk of hematologic toxicities with programmed cell death-1 inhibitors in cancer patients: a meta-analysis of current studies. Drug Des Devel Ther. 2018;12:1645-57. https://doi.org/10. 2147/DDDT.S167077.

9. Akhtari M, Waller EK, Jaye DL, Lawson DH, Ibrahim R, Papadopoulos NE, et al. Neutropenia in a patient treated with Ipilimumab (anti-CTLA-4 antibody). J Immunother. 2009;32:322-4. https://doi.org/10.1097/CJI. Ob013e31819aa40b.

10. Wei G, Nwakuche U, Cadavid G, Ajaz A, Seiter K, Liu D. Large granular lymphocytosis with severe neutropenia following ipilimumab therapy for metastatic melanoma. Exp Hematol Oncol. 2012;1:3. https://doi.org/10.1186/ 2162-3619-1-3.

11. du Rusquec P, Saint-Jean M, Brocard A, Peuvrel L, Khammari A, Quéreux G et al. Ipilimumab-induced autoimmune pancytopenia in a case of metastatic melanoma. J Immunother. 2014;37:348-50. https://doi.org/10. 1097/CJl.0000000000000041.

12. Simeone E, Grimaldi AM, Esposito A, Curvietto M, Palla M, Paone M, et al. Serious haematological toxicity during and after ipilimumab treatment: a case series. J Med Case Rep. 2014;8:240. https://doi.org/10.1186/1752-1947-8-240.

13. Woźniak S, Mackiewicz-Wysocka M, Krokowicz Ł, Kwinta Ł, Mackiewicz J. Febrile neutropenia in a metastatic melanoma patient treated with ipilimumab - case report. Oncol Res Treat. 2015;38:105-8. https://doi.org/10. $1159 / 000377650$

14. Ban-Hoefen M, Burack R, Sievert L, Sahasrabudhe D. Ipilimumab-Induced Neutropenia in Melanoma. J Investig Med High Impact Case Reports. 2016; 4:232470961666183. https://doi.org/10.1177/2324709616661835.

15. Tabchi S, Weng X, Blais N. Severe agranulocytosis in a patient with metastatic non-small-cell lung cancer treated with nivolumab. Lung Cancer. 2016;99:123-6. https://doi.org/10.1016/j.lungcan.2016.06.026.

16. Helgadottir $H$, Kis L, Ljungman P, Larkin J, Kefford R, Ascierto PA, et al. Lethal aplastic anemia caused by dual immune checkpoint blockade in metastatic melanoma. Ann Oncol. 2017;28:1672-3. https://doi.org/10.1093/annond/ $\mathrm{mdx} 177$.

17. Wright Z, Brown A. High-grade neutropenia in a patient successfully treated with nivolumab for refractory primary mediastinal B-cell lymphoma. Blood Adv. 2017;1:1306-8. https://doi.org/10.1182/bloodadvances.2017008607.

18. Turgeman I, Wollner M, Hassoun G, Bonstein L, Bar-Sela G. Severe complicated neutropenia in two patients with metastatic non-small-cell lung cancer treated with nivolumab. Anti-Cancer Drugs. 2017;28:811-4. https://doi.org/10.1097/CAD.0000000000000520.

19. Comito RR, Badu LA, Forcello N. Nivolumab-induced aplastic anemia: a case report and literature review. J Oncol Pharm Pract. 2019;25:221-5. https://doi.org/10.1177/1078155217726159.

20. Meyers DE, Hill WF, Suo A, Jimenez-Zepeda V, Cheng T, Nixon NA. Aplastic anemia secondary to nivolumab and ipilimumab in a patient with metastatic melanoma: a case report. Exp Hematol Oncol. 2018;7:6. https://doi.org/10.1186/s40164-018-0098-5.

21. Tokumo K, Masuda T, Miyama T, Miura S, Yamaguchi K, Sakamoto S, et al. Nivolumab-induced severe pancytopenia in a patient with lung adenocarcinoma. Lung Cancer. 2018;119:21-4. https://doi.org/10.1016/j. lungcan.2018.02.018.

22. Meti N, Petrogiannis-Haliotis T, Esfahani K. Refractory neutropenia secondary to dual immune checkpoint inhibitors that required second-line immunosuppression. J Oncol Pract. 2018;14:514-6. https://doi.org/10.1200/ JOP.18.00177.

23. Ariane B, Maliha PG, Hudson M, Small D. A case of severe Pembrolizumabinduced neutropenia. Anti-Cancer Drugs. 2018;29:1. https://doi.org/10.1097/ CAD.0000000000000661.

24. Tozuka T, Sugano T, Noro R, Takano N, Hisakane K, Takahashi S, et al. Pembrolizumab-induced agranulocytosis in a pulmonary pleomorphic carcinoma patient who developed interstitial lung disease and ocular myasthenia gravis. Oxford Med Case Reports. 2018;2018. https://doi.org/10. 1093/omcr/omy094.

25. Takahashi A, Kubo A, Mizuno S, Kasai K, Asai N, Yonezawa T, et al. Bicytopenia in primary lung melanoma treated with nivolumab. Intern Med. 2019.

26. Naqash AR, Appah E, Yang LV, Muzaffar M, Marie MA, McCallen JD, et al. Isolated neutropenia as a rare but serious adverse event secondary to immune checkpoint inhibition. J Immunother Cancer. 2019.

27. Delanoy N, Michot J-M, Comont T, Kramkimel N, Lazarovici J, Dupont R, et al. Haematological immune-related adverse events induced by antiPD-1 or anti-PD-L1 immunotherapy: a descriptive observational study. Lancet Haematol. 2019;6:e48-57. https://doi.org/10.1016/S23523026(18)30175-3.

28. Zimmer L, Goldinger SM, Hofmann L, Loquai C, Ugurel S, Thomas I, et al. Neurological, respiratory, musculoskeletal, cardiac and ocular side-effects of anti-PD-1 therapy. Eur J Cancer. 2016;60:210-25. https://doi.org/10.1016/j. ejca.2016.02.024

29. Bulbul A, Mustafa A, Chouial S, Rashad S. Idiopathic thrombocytopenic purpura and autoimmune neutropenia induced by prolonged use of nivolumab in Hodgkin's lymphoma. Ann Oncol Off J Eur Soc Med Oncol. 2017.

30. Sun Y, Lee SK, Oo TH, Rojas-Hernandez CM. Management of Immunemediated Cytopenias in the era of Cancer immunotherapy. J Immunother. 2018;41:32-4. https://doi.org/10.1097/CJI.0000000000000194.

31. Bryant AR, Perales MA, Tamari R, Peled JU, Giralt S. Severe pembrolizumabassociated neutropenia after CD34+ selected allogeneic hematopoietic-cell transplantation for multiple myeloma. Bone Marrow Transplant. 2018;53: 1065-8. https://doi.org/10.1038/s41409-018-0142-4.

32. Liu C, Ding L, Zhu Y, Chen C. A rare case of lung carcinoma acquires multidrug-resistant Klebsiella pneumoniae pneumonia radiologically mimicking metastasis caused by nivolumab therapy-associated neutropenia. Ther Clin Risk Manag. 2017;13:1375-7. https://doi.org/10.2147/TCRM.S144681.

33. Finkel I, Sternschuss M, Wollner M, Shamai S, Peled N, Turgeman I, et al. Immunerelated neutropenia following treatment with immune checkpoint inhibitors. J Immunother. 2019;00:1. https://doi.org/10.1097/CJl.0000000000000293.

34. Brahmer JR, Lacchetti C, Schneider BJ, Atkins MB, Brassil KJ, Caterino JM, et al. Management of Immune-Related Adverse Events in patients treated with immune checkpoint inhibitor therapy: American Society of Clinical Oncology clinical practice guideline. J Clin Oncol. 2018;36:1714-68. https://doi.org/10.1200/JCO.2017.77.6385.

35. Barnes PJ. Corticosteroid effects on cell signalling. Eur Respir J. 2006;27:413-26.

36. Andrès $\mathrm{E}$, Zimmer J, Mecili M, Weitten T, Alt M, Maloisel F. Clinical presentation and management of drug-induced agranulocytosis. Expert Rev Hematol. 2011;4:143-51. https://doi.org/10.1586/ehm.11.12.

37. Gaertner J, Stamer UM, Remi C, Voltz R, Bausewein C, Sabatowski R, et al. Metamizole/dipyrone for the relief of cancer pain: a systematic review and evidence-based recommendations for clinical practice. Palliat Med. 2017:31: 26-34. https://doi.org/10.1177/0269216316655746.

38. Petrelli F, Ardito R, Borgonovo K, Lonati V, Cabiddu M, Ghilardi M, et al. Haematological toxicities with immunotherapy in patients with cancer: 
a systematic review and meta-analysis. Eur J Cancer. 2018;103:7-16. https://doi.org/10.1016/j.ejca.2018.07.129.

39. Le Burel S, Champiat S, Mateus C, Marabelle A, Michot JM, Robert C, et al. Prevalence of immune-related systemic adverse events in patients treated with anti-programmed cell death 1/anti-programmed cell death-ligand 1 agents: a single-Centre pharmacovigilance database analysis. Eur J Cancer. 2017.

40. Linsley PS, Greene JL, Brady W, Bajorath J, Ledbetter JA, Peach R. Human B7-1 (CD80) and B7-2 (CD86) bind with similar avidities but distinct kinetics to CD28 and CTLA-4 receptors. Immunity. 1994;1:793-801. https://doi.org/ 10.1016/S1074-7613(94)80021-9.

41. Tumeh PC, Harview CL, Yearley JH, Shintaku IP, Taylor EJM, Robert L, et al. PD-1 blockade induces responses by inhibiting adaptive immune resistance. Nature. 2014;515:568-71. https://doi.org/10.1038/nature13954.

42. Mohty M. Mechanisms of action of antithymocyte globulin: T-cell depletion and beyond. Leukemia. 2007;21:1387-94. https://doi.org/10.1038/sj.leu.2404683.

43. Postow MA, Sidlow R, Hellmann MD. Immune-related adverse events associated with immune checkpoint blockade. N Engl J Med. 2018;378:158-68. https:/doi.org/10.1056/NEJMra1703481.

44. Johnston A, Uetrecht J. Current understanding of the mechanisms of idiosyncratic drug-induced agranulocytosis. Expert Opin Drug Metab Toxicol. 2015;11:243-57. https://doi.org/10.1517/17425255.2015.985649

45. Huber M, Andersohn F, Sarganas G, Bronder E, Klimpel A, Thomae M, et al. Metamizole-induced agranulocytosis revisited: results from the prospective Berlin case-control surveillance study. Eur J Clin Pharmacol. 2015;71:219-27. https://doi.org/10.1007/s00228-014-1777-8.

46. Metushi IG, Hayes MA, Uetrecht J. Treatment of PD-1 -/- mice with amodiaquine and anti-CTLA4 leads to liver injury similar to idiosyncratic liver injury in patients. Hepatology. 2015;61:1332-42. https://doi.org/10.1002/ hep.27549.

47. Sing C-W, Wong ICK, Cheung BMY, Chan JCY, Chu JKP, Cheung C-L. Incidence and risk estimate of drug-induced agranulocytosis in Hong Kong Chinese. A population-based case-control study. Pharmacoepidemiol Drug Saf. 2017;26:248-55. https://doi.org/10.1002/pds.4156.

48. Young A, Quandt Z, Bluestone JA. The balancing act between Cancer immunity and autoimmunity in response to immunotherapy. Cancer Immunol Res. 2018;6:1445-52. https://doi.org/10.1158/2326-6066.CIR-18-0487.

\section{Publisher's Note}

Springer Nature remains neutral with regard to jurisdictional claims in published maps and institutional affiliations.

Ready to submit your research? Choose BMC and benefit from:

- fast, convenient online submission

- thorough peer review by experienced researchers in your field

- rapid publication on acceptance

- support for research data, including large and complex data types

- gold Open Access which fosters wider collaboration and increased citations

- maximum visibility for your research: over $100 \mathrm{M}$ website views per year

At $\mathrm{BMC}$, research is always in progress.

Learn more biomedcentral.com/submissions 